J. Amer. Soc. Hort. Sci. 115(4):656-661. 1990.

\title{
Stigmatic Surface Degeneration and Inhibition of Pollen Germination with Selected Pesticidal Sprays during Receptivity in Pecan
}

\author{
Hazel Y. Wetzstein \\ Department of Horticulture, University of Georgia, Athens, GA 30602 \\ Additional index words. Carya illinoensis, flowering, fungicides, insecticides, pollination
}

\begin{abstract}
Commercial pesticide formulations of triphenyltin hydroxide, benomyl plus triphenyltin hydroxide, and phosalone completely inhibited pollen germination of pecan [Carya illinoensis Wangenh C. Koch] when incorporated in in vitro germination media at one-fourth to one times the recommended rates. Scanning electron microscopic evaluations of spray effects on receptive stigmatic surfaces showed varying degrees of injury, ranging from minor surface wrinkling with triphenyltin hydroxide to severe collapse and degeneration of stigma papillae with phosalone treatments. Controlled pollinations 1 hour after pesticide sprays resulted in an inhibition of pollen germination and tube growth. Water sprays followed by pollination resulted in normal pollen adherence, hydration, and germination. Chemical names used: methyl[1-[(butylamino)carbonyl]-1H-benzimidazol-2-yl]carbamate (benomyl); S-[(6-chloro-2oxo-3-(2H)-benzoxazolyl)methyl] 0,0-diethyl phosphorodithioate (phosalone).
\end{abstract}

Current recommendations for control of disease and insect pests in pecan include application of early season pesticides (Ellis et al., 1988). Preventive fungicidal sprays are advised to protect rapidly developing young foliage and to prevent establishment of disease in the orchard; insect and mite pests may necessitate early season application of insecticides. Thus, timing of pesticide applications frequently overlaps the pollination period. Adriance (1931), Hamilton (1942), and Woodroof et al. (1928) proposed that early season nut drop in pecan results from lack of pollination and hence absence of fertilization. This major period of drop, often referred to as May drop, coincides with the drop of bagged, unpollinated flowers.

Effects of pesticides on pollen germination and growth in pecan are unknown. Inhibitory effects of pesticidal sprays during pollination would be of particular concern in areas where pollination and fertilization are limiting factors in fruit production. Previous reports on the negative effect of agricultural pesticides on pollen germination and growth in fruit crops include observations with pear and apple (Church and Williams, 1977;

Received for publication 30 Oct. 1989. The cost of publishing this paper was defrayed in part by the payment of page charges. Under postal regulations, this paper therefore must be hereby marked advertisement solely to indicate this fact.
Legge and Williams, 1975; Marcucci et al., 1983; Marcucci and Filiti, 1984), blueberry (Bristow, 1981; Bristow and Windom, 1987), raspberry (Redalen, 1980), and cranberry (Bristow and Shawa, 1981; Shawa et al., 1966). However, we found no studies that determined how, or if, spray applications affect pollination in pecan. Meaningful extrapolations from the other crops to pecan culture are difficult due to differences in chemicals evaluated and divergences in reproductive strategy and morphology.

The majority of studies have evaluated pesticide effects on pollen germination using in vitro germination tests; relatively few have addressed the pollination response using in vivo systems. We found no reports on pesticide effects on stigma morphology and pollen-stigma interactions at the ultrastructural level. The objectives of this study were to evaluate the effects of selected pesticides on stigma receptivity and structure, pollen germination, and pollen tube growth, using in vitro germination tests and in vivo observations at the electron microscopic level.

\section{Materials and Methods}

In vitro germination tests. The pesticide combinations evaluated as commercial formulations and their recommended rates were: triphenyltin hydroxide (Du-Ter, Flowable 30, Griffin Corp., 
Valdosta, Ga.) $1.9 \mathrm{ml} \cdot$ liter $^{-1}$ water; Benomyl (Benlate, wettable powder, Dupont De Nemours, Wilmington, Del.) 600 $\mathrm{mg} \cdot$ liter $^{-1}$ water plus triphenyltin hydroxide $0.95 \mathrm{ml} \cdot$ liter $^{-1}$ water; and phosalone (Zolone, Rhone-Poulenc, Research Triangle Park, N.C.) $5 \mathrm{ml} \cdot$ liter $^{-1}$ water. Benomyl was evaluated in conjunction with triphenyltin hydroxide due to the recommendation that it not be applied alone (Ellis et al., 1988). Chemicals selected were widely used in pecan early season spray applications. For in vitro germination tests, pesticides were incorporated at onefourth, one-half, three-fourths, and one times the recommended rates into a-germination medium containing sucrose, $\mathrm{B}$, and agar (Wetzstein and Sparks, 1985). Catkins from 'Curtis' pecan trees were collected the afternoon before use and allowed to dehisce overnight in the laboratory. Pollen was collected and hydrated for $30 \mathrm{~min}$ in a humidified chamber before inoculation. Germination was evaluated 8 to $12 \mathrm{hr}$ later; 1,000 pollen grains per treatment were counted. Pollen was considered germinated if tubes grew longer than the pollen diameter.

Stigma morphology and pollen-stigma interactions. Distillate inflorescences were bagged (Gerhold, 1968) on 15-year-old 'Stuart' trees before receptivity to avoid open pollination. At receptivity, about 2 weeks later, l-year-old branches with attached shoots were removed. Their bases were put immediately in water. For laboratory observations of pesticide effects on the stigmatic surface, inflorescences were sprayed to runoff by use of a hand sprayer and with the same pesticides as used for in vitro germination tests at recommended rates. Distilled water sprays served as controls. Stigmas were examined at 2 to 4,6 to 8 , and 12 to $14 \mathrm{hr}$ after treatment. For microscopic observations, stigmas were excised, attached to aluminum stubs, and observed fresh and uncoated in a scanning electron microscope (Phillips 505 SEM); three to four flowers were observed for each treatment and time. For evaluations of pollen-stigma responses, pesticide- and water-treated flowers were hand pollinated $1 \mathrm{hr}$ after spraying. Flowers were observed 4 to $5 \mathrm{hr}$ after pollination, as described for microscopic study of the stigmatic surface. Flowers were also observed microscopically for browning 14 to $16 \mathrm{hr}$ after spraying.

\section{Results}

In vitro germination tests. Pesticide incorporation into the germination medium stopped pollen germination. There was no germination or tube growth with triphenyltin hydroxide or benomyl plus triphenyltin hydroxide treatments at any concentration. Pollen treated with phosalone at one-fourth the recommended rate exhibited early pollen tube emergence in 33 ' $\%$ of the grains, but further growth was arrested and tubes ruptured. At one-half the recommended rate, only $0.2 \%$ of the pollen grains exhibited emergence; at higher concentrations, there was no tube emergence. In contrast, $68 \%$ of the control pollen germinated, with extensive pollen tube growth.

Stigma morphology. The stigmatic surface of receptive pistillate flowers in pecan is comprised of raised papillate cells (Fig. 1A) covered by a mottled stigmatic exudate with electron light and dense areas. Stigmatic cells treated with water sprays showed water accumulation at cell interstices (Fig. 1B); however, most of the stigmatic surface had little or no water collection after a few hours. Stigmatic exudate remained evident with no apparent damage to surface cells (Fig. 1C).

Pesticide sprays deposited copious residues of spray material (Fig. $2 \mathrm{~A}, \mathrm{~B}$, and C) that were conspicuous after 2 to $4 \mathrm{hr}$ for all pesticide combinations. Papillae cell margins were embedded in spray residues with only the tips of papillate cells exposed.
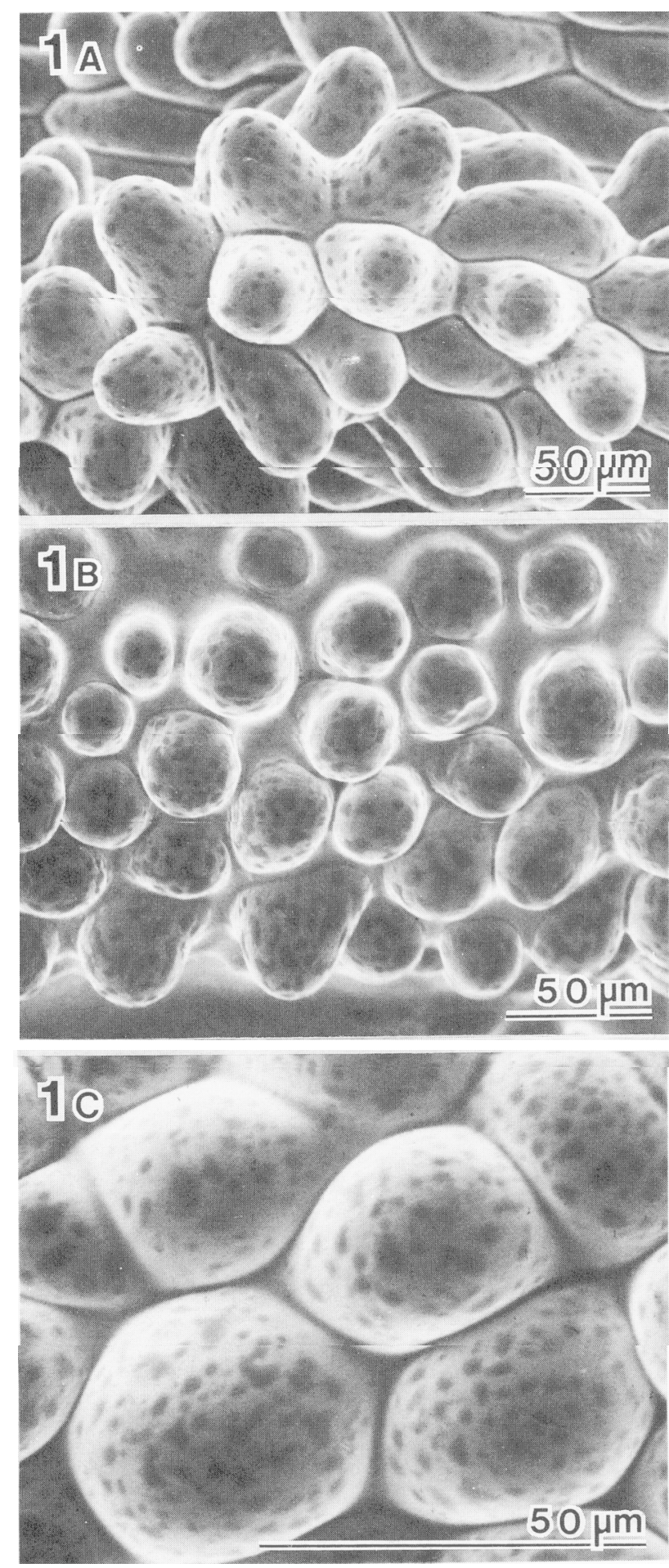

Fig. 1. Scanning electron micrographs of the stigmatic surface of pecan distillate flowers. (A) Papillate cells covered with a surface exudate of electron-dense and -translucent areas. (B) Stigmatic surface after treatment with a water spray showing papillate cell separation and accumulation at cell interstices. (C) Exudate is retained on water-sprayed stigmatic surface.

Stigmatic surfaces appeared moist. Flowers treated with triphenyltin hydroxide had dried surfaces lacking spray accumulation, clearly exposing the stigma by 6 to $8 \mathrm{hr}$ after treatment. In contrast, flowers treated with benomyl plus triphenyltin hydroxide combinations remained wet with copious deposits of 

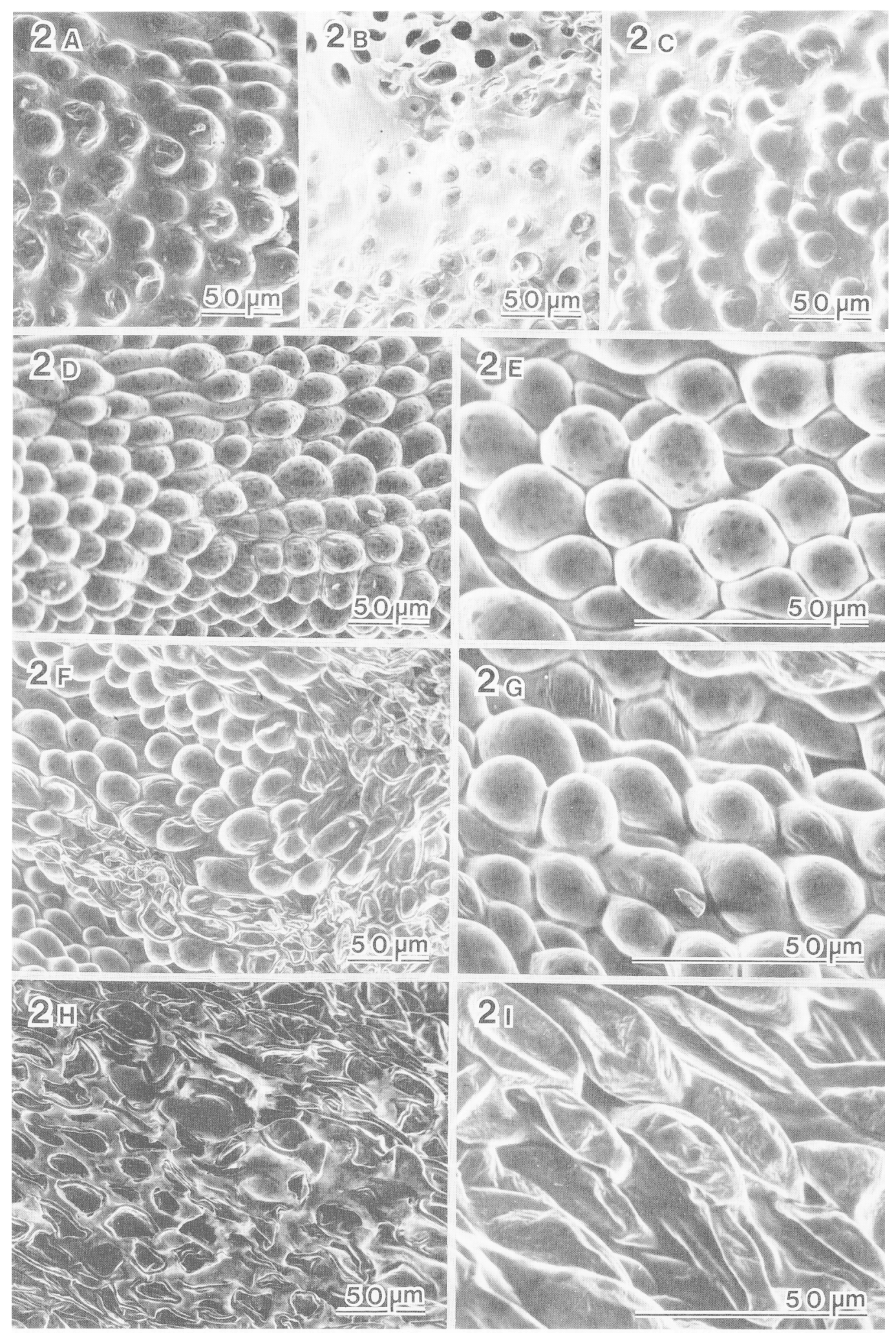

Fig. 2. Stigmatic surfaces of distillate flowers after pesticide spray applications. (A-C) Copious accumulations of pesticides were visible 2 to $4 \mathrm{hr}$ after application of triphenyltin hydroxide (A), benomyl in combination with triphenyltin hydroxide (B), and phosalone (C), respectively. (D) Stigma treated with triphenyltin hydroxide showing areas with minor wrinkling and injury of stigmatic cells, $7 \mathrm{hr}$ after treatment. (E) Higher magnification of triphenyltin hydroxide treatment; cells are generally intact with obvious stigmatic exudate. (F) Stigmatic surface of benomyl plus triphenyltin hydroxide treatment showing more extensive collapse and damage to surface cells, $13 \mathrm{hr}$ after treatment. (G) Higher magnification of treatment in (F); stigmatic exudate is masked by coverage of spray residue, $13 \mathrm{hr}$ after treatment. (H) Phosalone-treated stigma with extensive collapse of stigmatic cells, $8 \mathrm{hr}$ after treatment. (I) Phosalone-treated stigma, $13 \mathrm{hr}$ after treatment; cells are collapsed and lack visible stigmatic exudate. 
residue. Those treated with phosalone sprays were intermediate, having dry areas intermixed with areas exhibiting slight puddling of spray material. Stigmatic surfaces were dry 12 to 14 $\mathrm{hr}$ after application in all treatments.

Application of triphenyltin hydroxide caused areas of minor damage and wrinkling of stigmatic surface cells (Fig. 2D). However, stigmatic exudate was still evident on cell surfaces, and cells generally were intact with only minor damage 12 to $14 \mathrm{hr}$ after treatment (Fig. 2E). Benomyl plus triphenyltin hydroxide applications resulted in areas with more severe collapse of stigmatic surface cells (Fig. 2F) than triphenyltin treatments alone. Injury was apparent within 6 to $8 \mathrm{hr}$ after treatment. There was some browning in nonspecific areas of the stigma. After drying, stigmatic cells had a residual coating that veiled cell surfaces (Fig. 2G). Phosalone treatments resulted in extensive and severe injury of stigmatic cells (Fig. $2 \mathrm{H}$ ), evident within $8 \mathrm{hr}$ after treatment. Cells were flattened and degenerated, with some residue between collapsed cells; stigmatic exudate was obscured. Stigmatic exudate was also indistinct on severely damaged cells 12 to $14 \mathrm{hr}$ after treatment (Fig. 21). Stigmatic surfaces had extensive blackened areas visible to the unaided eye.

Pollen-stigma interactions. In controlled pollinations following water sprays, pollen grains adhered to the stigma, became hydrated, and germinated, exhibiting extensive pollen tube growth along the stigmatic surface (Fig. 3A). This sequence corresponds with normal events of compatible pollination in pecan (Wetzstein and Sparks, 1989). In contrast, pesticide spray applications inhibited pollen-stigma events. Pollen inoculated on triphenyltin hydroxide-treated stigmas hydrated; however, pollen tube emergence was arrested with little tube growth (Fig. $3 \mathrm{~B})$; germination and more extensive tube growth were infrequent (Fig. 3C). Benomyl plus triphenyltin hydroxide-treated flowers resulted in severe inhibition of pollen-stigma events. Pollen grains failed to hydrate, remained concave, and appeared engulfed in spray residue; tube emergence and germination were precluded (Fig. 3D). In contrast, on phosalone-treated stigmas, pollen became hydrated and tubes emerged within 4 to $5 \mathrm{hr}$, even on areas of the stigma where heavy spray residue was still present (Fig. 3E). Further pollen tube growth occurred in some grains; however, the frequency of pollen tube emergence and tube extension decreased. Stigmas observed at this time did not exhibit extensive damage apparent at later intervals.

\section{Discussion}

Early season pesticide sprays commonly used with pecan inhibit pollen germination and growth. Complete inhibition of germination in in vitro tests occurs with triphenyltin hydroxide, benomyl plus triphenyltin hydroxide, and phosalone, even at levels one-fourth the recommended rate of application. Inhibition of pollen germination in other fruit crops has been described with various pesticides when incorporated into or on the surface of pollen germination media. Inhibition of pollen germination has been described for in vitro germination studies with apple and pear (Church and Williams, 1977; Marcucci and Filiti, 1984; Marcucci et al., 1983), cranberry (Bristow and Shawa, 1981; Shawa et al., 1966; Redalen, 1980), and blueberry (Bristow, 1981; Bristow and Windom, 1987), often at levels well below recommended rates.

In this study, in vivo pollination of intact treated flowers inhibited pollen germination. However, results were less severe than with in vitro germination tests. Triphenyltin hydroxide treatments resulted in pollen hydration and tube emergence in vivo but not in vitro. Likewise, pollen tube emergence and limited extension were observed with in vivo phosalone treatments at rates that completely inhibited their appearance in in vitro germination tests. Pollen hydration on stigmatic surfaces was severely restricted with benomyl plus triphenyltin hydroxide sprays. The lack of pollen hydration and engulfment of pollen suggest that physical characteristics of the spray, in addition to phytotoxicity, may inhibit pollen germination.

These results concur with other in vivo tests of pesticides applied to receptive flowers in which inhibition of pollen germination and/or tube growth was found. Church and Williams (1977) reported adverse effects on pollen germination when fungicides were applied to apple stigmas. Marcucci et al. (1983) found pollen germination and tube growth in apple styles were inhibited in fungicide-treated flowers. The correlation between pollen tube length with fungicide on the medium and that with fungicide sprayed on the flowers was highly significant, although the effect was lower in vivo than in vitro. Pollen germination was inhibited when the fungicide triforine was applied to blueberry stigmas at recommended rates (Bristow, 1981). Bristow and Shawa (1981) reported that two of nine fungicide formulations tested lowered pollen germination in cranberry by $50 \%$ in vivo at concentrations equal to or less than those of suspensions recommended for field applications.

The relative timing of pollination and spray application may affect the extent of pesticide inhibition on pollen germination and tube growth. Apple flowers pollinated $2 \mathrm{hr}$ before fungicide spray applications had significantly reduced pollen germination; flowers pollinated $24 \mathrm{hr}$ before spraying exhibited no adverse effects (Church and Williams, 1977). In our studies with pecan, stigmas were pollinated within $1 \mathrm{hr}$ after spray treatments. Stigmas remained moist and displayed accumulations of spray residue at cell interstices. In contrast, under normal field applications of pesticides, pollination would likely occur over a longer period before and after spraying. The adverse effects of pesticides on early pollen-stigma events would probably be less than those in our studies. Whether they could affect fruit set or yield is unknown.

In addition to limitations on pollen germination and growth, these pesticides also injure stigmatic surface cells. Loss or masking of the stigmatic exudate, cell collapse, and loss of integrity could interfere with early pollen responses, including adherence, recognition, hydration, and germination. Pollen-stigma interactions and stigma structure in pecan are discussed in detail by Wetzstein and Sparks (1989). Varying degrees of stigmatic surface browning followed pesticide treatment; the associated injury would effectively decrease the receptivity of the female flower. The most severe injury was observed with phosalone treatments, followed by benomyl plus triphenyltin hydroxide, then triphenyltin hydroxide alone. It should be noted that phosalone, which caused the most severe stigmatic surface injury, had the least toxic effect on pollen germination.

Losses in fruit set, yield, and fruit quality have been attributed to field pesticide applications during pollination. Certain combinations of pesticides substantially decreased fruit set and yield, but not return bloom or fruit size in apple (Donoho, 1964). Legge and Williams (1975) note almost no fruit was set on apple inflorescences exposed to captan and binapacryl spray. Likewise, some fungicides significantly reduced yield in cranberry when applied during the blossoming period (Shawa et al., 1966; Bristow and Shawa, 1981). Pesticide-treated cranberry flowers 

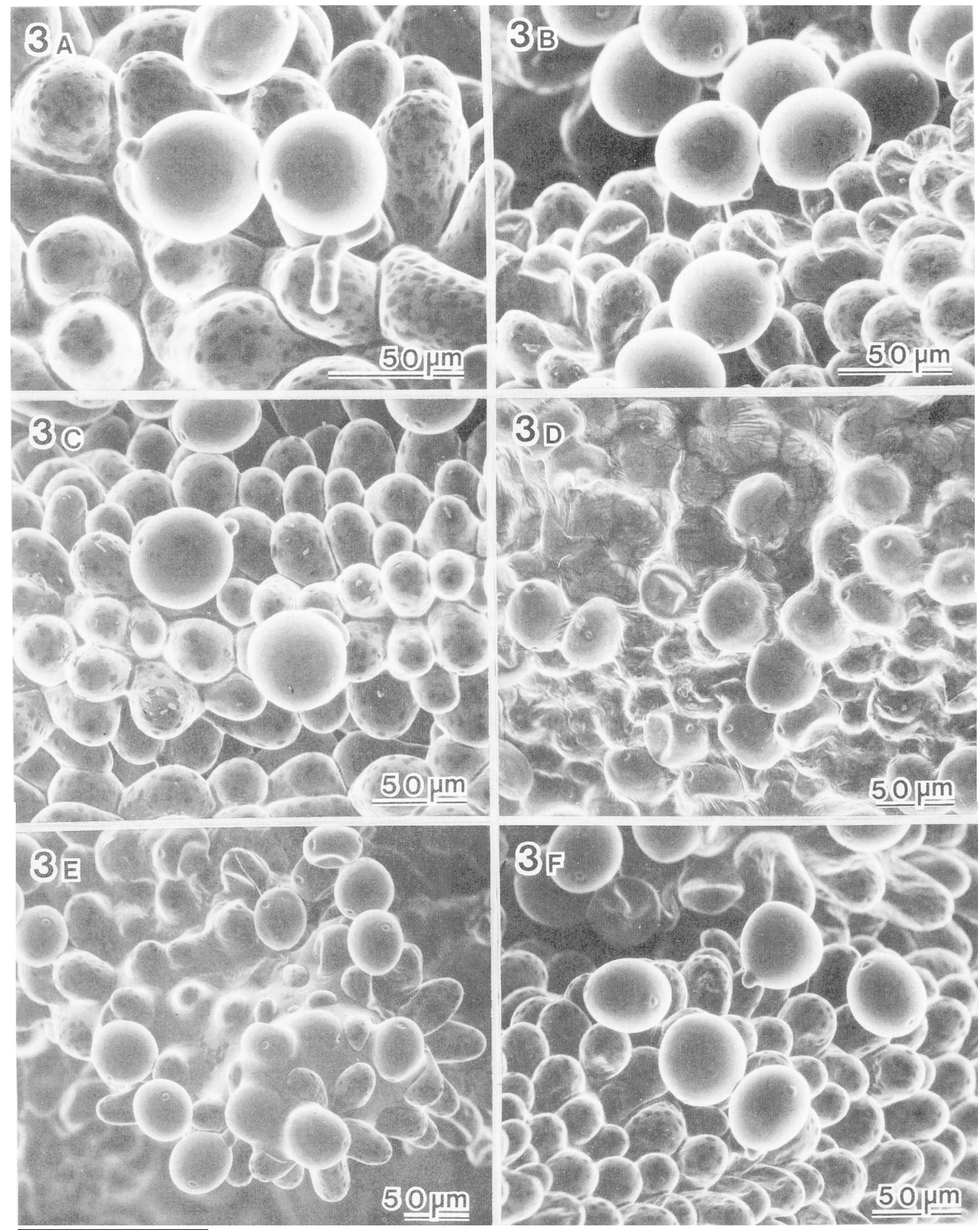

Fig. 3. Pollen germination and tube growth observed 4 to $5 \mathrm{hr}$ after controlled pollinations made $1 \mathrm{hr}$ after spray applications of pesticide or water. (A) Control water-sprayed distillate flower. Pollen has hydrated and germinated; note pollen tube extension along stigmatic cells. Surface cells have a conspicuous patterned exudate. (B) Pollination after triphenyltin hydroxide treatment; pollen is hydrated, but tube growth is inhibited. (C) As in (B), showing occasional pollen tube extension. (D) Pollen applied to benomyl plus triphenyltin hydroxide-treated stigma engulfed by spray residue; pollen is concave with inhibition of hydration and tube emergence. (E) Pollination after phosalone spray. Pollen grains hydrate and enlarge even in areas with persistent spray residues. (F) Treatment as (E), pollen tube emergence is visible, but tube growth is repressed compared to controls.

produced smaller fruit, suggesting reduced ovule fertilization (Bristow and Shawa, 1981). Pesticide sprays in raspberry caused a reduced druplet set per berry (Redalen, 1980).

The effects of these and other specific pesticides on stigma receptivity and pollen germination under field conditions for pecan have yet to be determined. Coverage of sprays using commercial sprayers and open pollinations under field conditions introduce conditions different from our laboratory studies. Most other studies report severe inhibition of pollen germination in vitro and decreased germination and tube growth in micro- 
scopic evaluations of treated flowers. However, fruit set and yield are not always similarly or consistently reported. Bristow (1981) suggests that flower morphology may play a role in pesticide susceptibility; e.g., a lack of inhibitory response to pesticide spray in blueberry but not in cranberry may reflect protection of anthers and stigmas by a corolla tube in the former, and exposed floral parts in the latter. Phytotoxicity may play a greater role in species where a high level of fruit set is necessary for a full crop (Bristow and Windom, 1987). Studies to ascertain the degree of pesticide inhibition in pecan under field conditions on fruit set and subsequent yield are needed, as are screenings to identify potentially less-toxic chemicals to apply during the pollination period.

\section{Literature Cited}

Adriance, G.W. 1931. Factors influencing fruit setting in the pecan. Bot. Gaz. 91:144-166.

Bristow, P.R. 1981. Effect of triforine on pollen germination and fruit set in highbush blueberry. Plant Dis. 65:350-353.

Bristow, P.R. and A.Y. Shawa. 1981. The influence of fungicides on pollen germination and yield of cranberry. J. Amer. Soc. Hort. Sci. 106(3):290-292.

Bristow, P.R. and G.E. Windom. 1987. Effects of selected fungicides, insecticides, and adjuvants on in vitro germination of highbush blueberry pollen. Plant Dis. 71:326-328.

Church, R.M. and R.R. Williams. 1977. The toxicity to apple pollen of several fungicides, as demonstrated by in vivo and in vitro techniques. J. Hort. Sci. 52:429-436.

Donoho, C.W., Jr. 1964. Influence of pesticide chemicals on fruit set, return bloom, yield, and fruit size of the apple. Proc. Amer. Soc. Hort. Sci. 85:53-59.

Ellis, H.C., P. Bertrand, T.F. Crocker, and C. Johnson. 1988. 1988 Georgia Pecan Spray Guide. Ga. Coop. Ext. Serv. Bul. 841. p. 14.

Gerhold, H.D. 1968. Mini-bags for tree breeding. Silvae Genet, 17:3132

Hamilton, J. 1942. Studies of the premature dropping of pecan nuts. Proc. Amer. Soc. Hort. Sci. 40:159-160.

Legge, A.P. and R.R. Williams. 1975. Adverse effects of fungicidal sprays on the pollination of apple flowers. J. Hort. Sci. 50:275277.

Marcucci, M.C. and N. Filiti. 1984. Germination of pear and apple pollen as influenced by fungicides. Gartenbauwissenschaft 49:2832.

Marcucci, M.C., M. Fiorentino, A. Cesari, and R. Fiaccadori. 1983. The influence of fungicides on the functioning of apple and pear pollen, p. 73-80. In: D.L. Mulcahy and E. Ottaviano (eds.). Pollen: biology and implications for plant breeding. Elsevier, Amsterdam.

Redalen, G. 1980. Effects of fungicides on pollen germination and fruit set in raspberries. Gartenbauwissenschaft 45(6):248-251.

Shawa, A.Y., C.C. Doughty, and F. Johnson. 1966. Effect of fungicides on McFarlin cranberry pollen germination and fruit set. Proc. Amer. Soc. Hort. Sci. 89:255-259.

Wetzstein, H.Y. and D. Sparks. 1985. Structure and in vitro germination of the pollen of pecan. J. Amer. Soc. Hort. Sci. 110(6 ):778781 .

Wetzstein, H.Y. and D. Sparks. 1989. Stigma-pollen interactions in pecan, Carya illinoensis. J. Amer. Soc. Hort. Sci. 114(2):355-359.

Woodroof, J.G., N.C. Woodroof, and J.E. Bailey. 1928. Unfruitfulness of the pecan. Ga. Expt. Sta. Bul. 148. 